\title{
DA DESCRIÇÃO À GRAMÁTICA DA 'PERCEPÇÃO' NO PERÍODO INTERMEDIÁRIO DE WITTGENSTEIN
}

\author{
FROM DESCRIPTION TO THE GRAMMAR OF 'PERCEPTION'IN \\ WITTGENSTEIN'S MIDDLE PERIOD
}

\author{
PAULO H.S. COSTA ${ }^{1}$ \\ Universidade Federal de Goiás (UFG) - Brasil \\ paulohscostabicalho@gmail.com
}

\begin{abstract}
RESUMO: Após retornar a Cambridge, em 1929, Wittgenstein se ocupa da formulação de um simbolismo perspícuo que expressasse, acuradamente, gradações. Dentre essas gradações estão as cores. Wittgenstein empreende-se na formulação de uma linguagem fenomenológica na qual questões relativas ao campo visual e à descrição perspícua de fenômenos seriam centrais. A ideia de descrição, por meio de um simbolismo, era assegurada para que proposições que envolvessem graus tivessem uma análise final. Com o abandono do projeto fenomenológico, por volta de 1929/30, Wittgenstein migra da fenomenologia à gramática e se ocupa, a partir das Observações Filosóficas e sobretudo no Big Typescript, da gramática da "percepção". A gramática, diferente do simbolismo de 1929, não se ocupa da descrição de fenômenos, mas de evitar a formulação de absurdos. Nesta mudança de posição se encontra, em especial, o novo tratamento dado pelo filósofo à generalidade e à análise.
\end{abstract}

PALAVRAS-CHAVE: Descrição. Gramática. Percepção.

ABSTRACT: After his return to Cambridge in 1929, Wittgenstein busied himself with the formulation of a perspicuous symbolism that accurately expresses gradations. Among these gradations are colors. Wittgenstein embarked upon the formulation of a phenomenological language in which questions related to the visual field and perspicuous description of phenomena would be central. The idea of description, through symbolism, is ensured so that propositions involving gradations have a complete analysis. With the abandonment of the phenomenological project, around 1929/30, Wittgenstein migrates from phenomenology to grammar. Beginning with Philosophical Remarks and above all in The Big Typescript, he busies himself with the grammar of "perception". Grammar; unlike the symbolism of 1929, is not concerned with describing phenomena, but with avoiding the formulation of absurdities. In this change of position, we find, in particular, the new treatment given by the philosopher to generality and to analysis.

KEYWORDS: Description. Grammar: Perception.

\footnotetext{
${ }^{1}$ Doutorando em Lógica e Filosofia da Linguagem pela Universidade Federal de Goiás (UFG).
} 


\section{INTRODUÇÃO}

"A percepção é um problema filosófico", é o que nos diz a tradição filosófica. ${ }^{2}$ Contudo, dizer isto de antemão é estranho. Afinal, como poderia algo que nos parece ser tão próximo, a percepção, ser um problema - e, ainda, ser um problema filosófico? O fato de que podemos ter percepções distintas (seja lá o que ela for) não parece, a rigor, ser suficiente para nos garantir que há um problema com a percepção. Temos também opiniões distintas e nem por isso podemos alegar que há um problema inerente à falta de consenso, tampouco um problema filosófico. Portanto, devemos ter em mente que a palavra 'percepção' é usada aqui, neste texto, de modo diferente do seu uso comum. Não estamos interessados, ao menos em um primeiro momento, em saber se a percepção envolve falhas e se estas falhas estão relacionadas ao modo como as coisas são ou ao modo como elas são percebidas, como faz a tradição. ${ }^{3}$ Estamos interessados, por um lado, na palavra 'percepção' (no problema filosófico da percepção como um problema conceitual/gramatical) e, por outro lado, na percepção como um problema relativo à percepção visual (ao campo visual). É este, inclusive, o objetivo de Wittgenstein no período intermediário. ${ }^{4}$

Seu interesse, como dissemos, refere-se à percepção visual e ao problema do campo visual. Não queremos sustentar, com isso, que Wittgenstein restringe o problema da percepção ao problema da percepção visual, sobretudo, do campo visual. Apenas estamos tratando, neste texto, da relação entre o problema da percepção visual e o problema da gramática da 'percepção'. Wittgenstein tenta tratar deste problema a partir de uma análise conceitual (gramatical) porque entende, como diz mais tarde no Big Typescript, que "ninguém pode nos ensinar a conhecer melhor o nosso próprio espaço visual. Mas podemos aprender a obter uma visão geral de sua representação linguística" (BT 444). Seria absurdo, em certo sentido, ter uma teoria que nos ensinasse como devemos (ou deveríamos) usar o campo visual. Mas não é absurdo pensar, por outro lado, em uma teoria que trate do modo como usamos (às vezes de maneira incorreta) o campo visual, e como, por exemplo, podemos "distinguir uma investigação geométrica a partir de uma investigação de um processo no espaço visual” (BT 444).

Na primeira seção deste texto iremos tratar da questão da percepção como um problema relativo à percepção visual, e mostrar como o problema ganha forma, em 1929, com o artigo Algumas Observaçôes sobre a Forma Lógica e nas Observações Filosóficas em 1929-30. Argumentaremos que a tentativa de se criar um simbolismo perspícuo para gradações em 1929 leva Wittgenstein a entender o projeto da linguagem fenomenológica como uma espécie de descrição dos fenômenos (mas diferente do que é empreendido, por exemplo, pela fenomenologia de Husserl). ${ }^{5}$ A descrição feita por Wittgenstein é

\footnotetext{
2 Agradeço aos comentários de Acríssio Gonçalves e também às sugestões do prof. André Porto à primeira versão deste texto.

3 Cf. Austin (2004) e Branquinho (2014).

${ }^{4}$ E também, pode-se dizer, nas Investigações Filosóficas. Na seção XI, por exemplo, Wittgenstein diz claramente que a percepção, suas causas, "interessam aos psicólogos. A nós interessa o conceito e sua posição no meio dos conceitos empíricos" (WITTGENSTEIN, 1999, p. 117, grifos nossos).

${ }^{5}$ Cf. Moreno (2003).
} 
simbólica/notacional e tem como objetivo levar a cabo a análise proposicional de proposições que envolvem gradação por meio de um sistema de coordenadas. Na segunda seção iremos tratar da questão da percepção como um problema de ordem gramatical, sobretudo, no Big Typescript (1932-33) e no texto Linguagem Fenomenológica (1931-34). Argumentaremos que Wittgenstein, a partir do abandono da tese da linguagem fenomenológica, passa da fenomenologia à gramática. A ideia de descrição, portanto, migra de uma noção simbólica/notacional para um arranjo de diferentes sistemas gramaticais, independentes e não concorrentes entre si, que, de modo normativo, determinam o que faz sentido dizer ou não sobre proposições (em especial, como em 1929, sobre aquelas proposições que envolvem graus). Tentaremos mostrar, assim, como o uso de diferentes sistemas gramaticais (como aqueles que descrevem o campo visual e aqueles que descrevem fatos no mundo) criam, via analogias enganadoras, falsos problemas para a questão da percepção. Além disso, tentaremos mostrar como essa nova noção de descrição tem um impacto para o tratamento da generalidade e da análise.

\section{Da Descrição: Linguagem Fenomenológica e PercepÇão Visual}

Quando Wittgenstein retorna a Cambridge, em 1929, seu interesse, como ele mesmo diz, refere-se ao estudo do campo visual. ${ }^{6}$ Após as críticas apresentadas por Ramsey, em 1923, à tese da independência lógica das proposições elementares do Tractatus, a partir do contraexemplo das cores, Wittgenstein elabora um pequeno artigo, Algumas Observações Sobre a Forma Lógica (1929), no qual pretende criar um simbolismo perspícuo para tratar do campo visual. A partir deste artigo surge o projeto da linguagem fenomenológica.

Diferentemente do Tractatus, onde não se era claro, ao certo, o estatuto das proposições elementares, ${ }^{8}$ Wittgenstein assume explicitamente em 1929 que se trata de fenômenos. Uma análise completa das proposições ordinárias seria aquela que, ao fim, descreveria a "multiplicidade lógica" dos fenômenos. Por "multiplicidade lógica" Wittgenstein se refere aqui à multiplicidade dos fenômenos. No Tractatus, por meio da ideia de análise lógica, Wittgenstein sustentava que toda proposição complexa deveria ser decomposta em proposições elementares. As

${ }^{6}$ Wittgenstein diz a Waismann que retornou a Cambridge para trabalhar com o "espaço visual e outras coisas" (WAISMANN, 1979, p. 17).

${ }^{7}$ Ramsey critica a tese da existência de proposições elementares que se excluem, mas que são, aparentemente, uma a negação da outra, do tipo, "Este livro é azul" e "Este livro é vermelho". Para Ramsey, Wittgenstein deveria demonstrar que seria possível determinar, de modo a priori, o valor de verdade dessas proposições caso quisesse continuar sustentando, como no Tractatus, que toda necessidade é uma necessidade lógica (1923, pp. 272-277).

${ }^{8}$ Wittgenstein, no Tractatus, não ofereceu nenhum exemplo de proposição elementar, nem levou a cabo o processo de análise proposicional. Isso criou uma disputa acerca da natureza das proposições elementares e de seus fazedores de verdade (truth-makers). Nos Notebooks (1914-16), por exemplo, algumas passagens sugerem que haveria um minima sensibilia que determinaria, com precisão, o que uma proposição descreveria (uma clara defesa fenomenológica dos estados de coisas elementares); outras, no entanto, sugerem que eles seriam pontos materiais (ou seja, uma clara defesa fisicalista). Embora não tenha deixado claro qual posição o Tractatus deveria assumir (apesar de sustentar, aparentemente, um sistema de coordenadas), Wittgenstein só vem a tratar destas questões, de fato, em 1929. 
proposições elementares seriam funções de verdade das proposições complexas. De modo similar ocorreria com os fenômenos. Se uma proposição elementar é composta, diretamente, pela ligação entre objeto simples e nomes simples, então ela representa um evento elementar, ou, nos termos do Tractatus, um estado de coisas atômico. Nesse sentido, a análise lógica do Tractatus seria feita pela decomposição da proposição e também pela decomposição do evento (evento geral) em subeventos (em estado de coisas atômicos). Deste modo, um conjunto de subeventos estaria em ligação direta a um conjunto de proposições elementares. A análise, nestes termos, é exatamente a eliminação da multiplicidade por meio da eliminação da generalidade.

No artigo de 1929, no entanto, Wittgenstein assume que esta análise deveria ser realizada de modo "a posteriori e não por conjecturas sobre possibilidades a priori' como pensara no Tractatus (1993, p. 30). Wittgenstein reconhece, assim, que a forma verocondicional da análise proposicional não deveria ser aplicada irrestritamente a todas as proposições porque, afinal, não haveria uma única forma lógica por detrás que as unificaria, conforme sustentara no Tractatus. Dito de outra forma, haveria algumas proposições que não poderiam ser decompostas e, por isso, não poderiam ser analisadas em termos verofuncionais. A proposta de Wittgenstein seria, então, a construção de uma linguagem (um simbolismo perspícuo) que tratasse deste tipo de proposições. Mas, de quais proposições, de fato, Wittgenstein está falando?

Uma antiga forma de ver a questão, como sugere Wittgenstein, é pensar na dicotomia lei de projeção e tradução. Numa lei de projeção podemos projetar as figuras de um plano I nas figuras do plano II - "digamos, a da projeção ortogonal ou qualquer outra - e, em seguida, passar a projetar sobre II todas as figuras de I em conformidade com essa lei" (WITTGENSTEIN, 1993, p. 30). Pela regra de tradução podemos dizer que determinada figura no plano I refere-se à determinada figura no plano II - "que toda elipse no plano I deve aparecer como um círculo no plano II" (Ibidem). O problema em ambas as posições se refere ao fato de que se partirmos delas (do plano II), não é possível inferir imediatamente "os formatos exatos das figuras originais no plano I" (Ibidem). ${ }^{9}$ O problema, portanto, é que usamos essas "formas" para representar diferentes coisas, de várias maneiras, sendo que a rigor a estrutura sujeito-predicado de nossas representações não nos permite tirar "conclusões - salvo muito vagas - acerca da verdadeira forma lógica dos fenômenos descritos"; afinal, formas como "este artigo é chato" ou o "tempo está bom" ou ainda "eu sou preguiçoso" nada têm em comum entre si, exceto o fato de se apresentarem, aparentemente, com a mesma forma sujeito-predicado (Ibidem).

Para conseguir levar a cabo a análise destas proposições, sobretudo, as que envolvem gradações, Wittgenstein abandona a tese tractariana de que proposições elementares têm a forma função-argumento, porque, como ele mesmo diz, elas funcionariam como sujeito-predicado. Wittgenstein precisa, portanto, de uma nova

9 "O problema é que não podemos inferir a forma de uma figura projetada apenas da forma da imagem projetada dessa imagem. Deve-se levar em conta o método de projeção" (MACHADO, 2004, p. 186). 
maneira de levar a cabo a análise deste tipo de proposição. Precisa, então, de uma nova linguagem, de um novo simbolismo. Wittgenstein sustenta, portanto, que a linguagem ordinária, baseada na forma sujeito-predicado, descreveria os estados de coisas de forma geral, sem qualquer cuidado com detalhes na sua representação. Em contrapartida, "a linguagem fenomênica, constituindo a estrutura lógica das proposições gerais, descreveria o fenômeno representando sua multiplicidade exata" (GOMES, 2011, p. 35). O pano de fundo desta posição nos diz que a análise proposicional seria a descrição completa dos fenômenos. Dessa forma, a análise proposicional passaria a ser concebida como o processo no qual "as descrições da linguagem ordinária seriam traduzidas em uma linguagem fenomênica” (Ibidem, grifos nossos). Nesta tradução das proposições ordinárias em proposições fenomenológicas, a estrutura dos fenômenos seria descrita, de modo que os dados perceptuais, ao fim, determinariam o sentido das proposições elementares.

Para tratar da forma lógica dos fenômenos, de sua multiplicidade, teríamos de ter um simbolismo perspícuo que considerasse em seu sistema gradações. Ou seja, um sistema que considerasse as "formas de espaço e tempo [juntamente] com todo o múltiplo de objetos espaciais e temporais, como cores, sons, etc., etc., com suas gradações, transições contínuas e combinações em várias proporções [...]" (WITTGENSTEIN, 1993, p. 31). Uma linguagem que representasse, portanto, os fenômenos reais. Ou melhor, uma linguagem que descrevesse os fenômenos reais. Afinal, proposições ordinárias que versam sobre objetos espaciais e temporais envolvem normalmente gradações. ${ }^{10}$ Se alguém nos perguntar, como argumenta Wittgenstein, "qual é a temperatura lá fora?" responderíamos que "faz vinte e sete graus". Não faz sentido, neste contexto, que o interlocutor nos pergunte novamente "faz trinta e dois graus?" porque responderíamos naturalmente que "já disse que faz vinte e sete graus". Proposições que envolvem graus são, nesse sentido, descrições completas. Elas não exigem análise, pois seriam, como diz Wittgenstein, "de certo modo tautologias" (1993, p. 31). Afinal, dizer "faz vinte e sete graus" é dizer "que a temperatura é vinte e sete". Neste caso, o grau de uma proposição exclui a outra - se faz vinte e sete não faz vinte e oito ao mesmo tempo, nem trinta e dois. Nesse sentido, se elas são completas, não são formadas por outras proposições. A análise proposicional destas proposições, portanto, não se baseia numa análise verocondicional. "Talvez alguém pense - não faz muito tempo, eu pensava assim - que uma asserção que exprime o grau de uma qualidade possa ser analisada num produto lógico de asserções de quantidade isoladas" (WITTGENSTEIN, 1993, p. 34, grifos nossos).

Uma maneira adequada de expressar esta "propriedade de completude" seria estabelecer, como sugere Wittgenstein, um sistema de coordenadas no qual números devessem entrar na estrutura das proposições elementares. Este sistema descrevia o próprio campo visual.

\footnotetext{
${ }^{10}$ Cf. Gonçalves (2016).

${ }^{11}$ Wittgenstein diz, textualmente, que se essas proposições que envolvem graus são completas, então não podem ser decompostas. Mas, nada diz sobre o fato de, pela combinação verocondicional, podermos ou não formar proposições mais complexas a partir dessas proposições completas.
} 


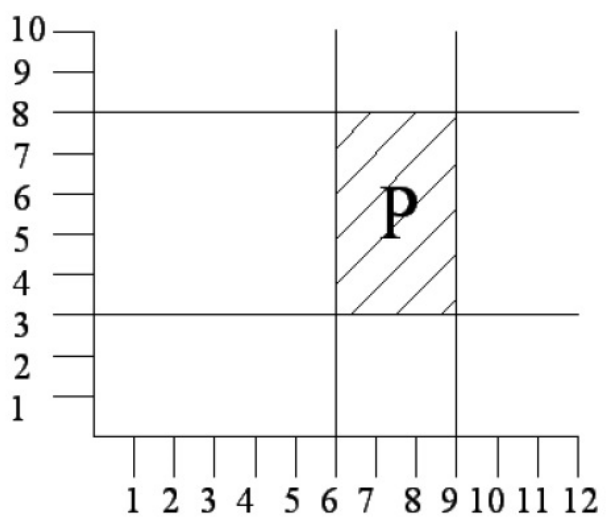

Figura 1

Se imaginarmos um sistema de coordenadas definido por eixos (um horizontal e outro vertical), podemos representar, claramente, uma mancha "P" no sistema. A coordenada, por exemplo, "[6-9,3-8]", representa a multiplicidade lógica da mancha "P" dentro do sistema - a coordenada "6-9" representa a posição da mancha no eixo horizontal e a coordenada "3-8" representa a posição da mancha no eixo vertical. Sabemos, assim, que se a mancha "P" está na coordenada "[6-9,38]" e atribuímos a ela a proposição "P é vermelha", então não poderíamos obter, simultaneamente, uma proposição do tipo "P é vermelha e verde" para esta mesma coordenada. O sistema de coordenadas, neste caso, seria "parte do modo de expressão [...] parte do método de projeção com que a realidade é projetada no simbolismo" (WITTGENSTEIN, 1993, p. 32). A importância de um sistema deste tipo se baseia no fato de que ele expressa, como quer Wittgenstein, a diversidade que a forma lógica da linguagem deveria ter, sobretudo, em relação à análise dos fenômenos visuais.

Quando Wittgenstein diz "descrever os fenômenos", ele diz:

[...] somente conseguimos substituir o simbolismo impreciso por um claro ao examinarmos os fenômenos que desejamos descrever, procurando deste modo entender a multiplicidade lógica deles.

[...] partindo do uso dessas normas (sujeito-predicado), não podemos tirar conclusões - salvo muito vagas - acerca da verdadeira forma lógica dos fenômenos descritos (Ibidem, p. 30, grifos nossos).

A ideia de descrição aqui é exclusivamente notacional. O simbolismo do sistema de coordenadas que, em sua forma, é expresso por números, descreve completamente a gradação que o fenômeno "[6-9,3-8] v" comunica, a saber, que a mancha "p", no campo visual, na coordenada "[6-9, 3-8]", é "vermelha". A descrição do fenômeno é notacional e, neste caso, completa. Mas, embora a descrição seja completa, o simbolismo do sistema de coordenadas não é completo e perspícuo, porque não inclui, por exemplo, o tempo (não diz que a coordenada "[6-9,3-8]" está no tempo $\mathrm{t}_{1}$ e não no tempo $\mathrm{t}_{2}$ ). O simbolismo apenas expressa, claramente, a gradação do fenômeno ao mostrar que números devem ser incluídos em sua 
notação para que fenômenos possam ser de fato descritos. O motivo, como já dissemos, diz respeito à gradação - "uma característica dessas propriedades é que um grau delas exclui qualquer outro. Um matiz não pode ter simultaneamente dois graus diferentes de brilho ou vermelhidão; uma nota, duas intensidades diferentes etc." (Ibidem, p. 33, grifos nossos). Sabemos que isso não pode ocorrer não por causa de nossa experiência exclusivamente (embora no dia a dia nos deparamos com situações deste tipo), mas porque em nossa notação vemos que estes casos não poderiam ocorrer. Para Wittgenstein, portanto, "a relação de diferença de grau é uma relação interna”, i.e., é uma relação necessária (Ibidem, p. 32, grifos nossos).

Se dissermos, como faz Wittgenstein, que existe uma cor R num certo tempo T e num certo lugar L no campo visual, então a proposição "RLT" expressa uma coordenada. Se dissermos, por outro lado, que a proposição "BLT" diz que a cor B está no lugar L no tempo T, sabemos, de antemão, que "RLT \& BLT" não poderia ocorrer. O próprio simbolismo nos mostra esta impossibilidade. No entanto, como diz Wittgenstein, tendemos a assumir que a proposição "RLT \& BLT" é algum tipo de contradição e não apenas uma proposição falsa. Dizemos isto porque assumimos cada coordenada que envolve grau deste tipo como completa, estabelecendo uma distinção apenas na função "( ) LT" em que, no lugar vazio, inserimos a entidade (e apenas ela). O antigo simbolismo do Tractatus nos diria, então, que esta proposição "RLT \& BLT" não nos fornece uma figuração correta da realidade. O problema, no entanto, é que a proposição "RLT \& BLT" não é contraditória, conforme o próprio simbolismo do Tractatus, de modo incorreto, sustentava (ou sustentaria). Ela, na verdade, nem deveria ocorrer porque "RLT" exclui "BLT".

As proposições 'Brown está sentado agora nesta cadeira' e 'Jones está sentado agora nesta cadeira', cada uma tenta, de certo modo, colocar na cadeira o seu sujeito lógico. Porém, o produto lógico dessas proposições colocará os dois lá de uma vez, o que leva a uma colisão, uma exclusão mútua desses termos (Ibidem, p. 34, grifos nossos).

Para poder expressar corretamente este caso da exclusão mútua, Wittgenstein sustenta que "não há produto lógico de RLT e BLT", pois, se existisse teríamos um contrassenso.

\begin{tabular}{|c|c|c|c|c|c|c|c|}
\hline \multicolumn{3}{|c|}{ Simbolismo do TLP } & \multicolumn{2}{|c|}{$\begin{array}{l}\text { Exclusão da } 1 \text { a } \\
\text { Linha }\end{array}$} & \multicolumn{3}{|c|}{ Contrassenso } \\
\hline$P$ & $\mathrm{Q}$ & & RLT & BLT & RLT & BLT & \\
\hline$V$ & $V$ & $V$ & - & - & $V$ & $V$ & $F$ \\
\hline $\mathrm{V}$ & $\bar{F}$ & $\mathrm{~F}$ & $\mathrm{~V}$ & $\mathrm{~F}$ & $\overline{\mathrm{V}}$ & $\mathrm{F}$ & $\mathrm{F}$ \\
\hline $\mathrm{F}$ & $\mathrm{V}$ & $\mathrm{F}$ & $\mathrm{F}$ & V & $\mathrm{F}$ & V & $\mathrm{F}$ \\
\hline $\mathrm{F}$ & $F$ & $\bar{F}$ & $\bar{F}$ & $\mathrm{~F}$ & $\bar{F}$ & $F$ & $F$ \\
\hline
\end{tabular}

Tabela 1 
A tabela mostra, como dissemos no início da seção, que a teoria verocondicional do Tractatus não se aplica irrestritamente a todos os casos. No Tractatus, o que Wittgenstein diz sobre as cores é que "duas cores estejam ao mesmo tempo num lugar do campo visual é impossível e, na verdade, logicamente impossível, pois a estrutura lógica das cores o excluí (6.3751, grifos nossos). Wittgenstein, portanto, parece antecipar alguns problemas que seriam apresentados em 1929. Mas, em 1921, ele ainda não diz nada sobre a possibilidade de um simbolismo fenomenológico. Não diz, neste caso, que em proposições que envolvem gradação, como no caso das cores, teríamos de ter um simbolismo mais perspícuo que expressasse, com clareza, a análise dos fenômenos. Assim, neste simbolismo teríamos de aceitar, de forma contrária ao Tractatus, que certas proposições elementares não são logicamente independentes, além de aceitar que proposições que envolvem graus são completas e, portanto, não podem ser analisadas (no sentido de decompostas em outras proposições). Wittgenstein propõe com o artigo de 1929, portanto, a construção de uma linguagem fenomenológica. O projeto de construção de uma linguagem fenomenológica, no entanto, foi abandonado alguns meses depois.

Não iremos tratar a fundo dos motivos que levaram Wittgenstein a abandonar o projeto da linguagem fenomenológica. De maneira geral, o sistema de coordenadas proposto por ele, em 1929, funcionaria como um simbolismo perspícuo para tratar de proposições relativas ao campo visual em oposição às proposições relativas à linguagem ordinária. No entanto, mesmo quando os fenômenos são assumidos isoladamente no campo visual, livre de hipóteses, eles parecem expressar uma ambiguidade intrínseca que o simbolismo não consegue eliminar.

Essa ambiguidade é encontrada em nossa apreensão do campo visual e de sua "geometria". Quando Wittgenstein diz que "não existe medição no campo visual" (PB 212), tem em mente uma medição interna ao mesmo. Toda determinação de vagueza ou ambiguidade presente no campo visual pressupõe um parâmetro externo. No entanto, se o parâmetro é externo, a apreensão passa a ter um caráter hipotético - e não mais imediato, como era requerido (ENGELMANN, 2013, p. 10).

O sistema de coordenadas não trata, por exemplo, da impossibilidade da mistura da cor vermelha com a verde, do que faz sentido ou não afirmar. Apenas diz que uma proposição, do tipo, "A é vermelho e A é verde" não poderia ocorrer simultaneamente. Há, neste caso, uma restrição espaço-temporal. Portanto, o simbolismo perspícuo do sistema de coordenadas funcionaria apenas parcialmente. Ele não trata, de fato, da multiplicidade lógica dos fenômenos. Não há para o campo visual, como vimos na passagem acima, uma delimitação interna - que, aqui, devemos entender como necessária. Além disso, o campo visual não permite que se faça "uma imagem visível da imagem visual, pois não se pode duplicá-lo "sob pena de perder sua autonomia, de passar a ter um dono" e, 
portanto, de não ser uma representação perspícua (SILVA, 2000, p. 90). ${ }^{12}$ Desse modo, como Wittgenstein não poderia levar a cabo a análise dessas proposições, o projeto da linguagem fenomenológica é abandonado. Afinal, sem uma análise completa, a linguagem fenomenológica não poderia ser um complemento da notação verocondicional do Tractatus, nem do sistema de coordenadas de $1929 .{ }^{13}$

\subsection{Sua "Gramática é Completamente Esclarecida"}

Nas Observações Filosóficas, em 1930, Wittgenstein não estava mais preocupado com um simbolismo perspícuo que representasse os fenômenos "Agora já não tenho como objetivo a linguagem fenomenológica, ou a linguagem primária”" (WITTGENSTEIN, 2005, p. 37). A completa determinação (ou completa descrição) da análise fenomenológica da linguagem, por meio de uma linguagem fenomenológica, é transporta para a análise gramatical - "Uma proposição é analisada completamente em termos lógicos se sua gramática é completamente esclarecida" (Ibidem, grifos nossos). Wittgenstein se ocupa, nesta nova fase, de uma gramática-fenomenológica. ${ }^{14}$ Essa gramática-fenomenológica teria como função esclarecer as regras implícitas que governariam a gramática da qual nos ocupamos na linguagem. Ao esclarecê-las saberíamos, portanto, o que faz sentido ou não afirmar. Saberíamos quais proposições teriam sentido e quais seriam absurdas porque a própria gramática iria perspicuamente nos mostrar.

A proposta de Wittgenstein com o projeto da gramática-fenomenológica pretendia "separar o que é essencial do que não é essencial em nossa linguagem" (WITTGENSTEIN, 2004, p. 37). Uma maneira de se fazer essa separação, acredita Wittgenstein, refere-se à distinção entre a linguagem física e a fenomenológica.

A física difere da fenomenologia pelo fato de estar interessada em estabelecer regras. A fenomenologia só estabelece possibilidades. Assim, a fenomenologia seria a gramática da descrição dos fatos sobre os quais a física constrói suas teorias (Ibidem, grifos nossos).

As proposições da nossa linguagem são sempre do mesmo tipo que as proposições da física e não do mesmo tipo que as proposições "primárias" que tratam do que é imediato (Ibidem, grifos nossos).

\footnotetext{
${ }^{12}$ Wittgenstein considera que o conceito de 'campo visual' é totalizante. Ou seja, não faz sentido individualizá-lo, dizendo, assim, que cada um tem seu próprio campo visual. A proposta de Wittgenstein, portanto, é a construção de um simbolismo perspícuo que descreveria o campo visual. Por isso, como diz Silva, se duplicamos o campo visual podemos incorrer na tese de que cada pessoa tem (ou teria) seu próprio campo visual. Se isto ocorre, não faz sentido um simbolismo perspícuo, afinal, as condições de cada campo visual seriam bem distintas, de modo que o sistema de coordenadas deveria considerar inúmeras gradações (tempo, espaço, direção, etc.).

13 Cf. Engelmann (2013).

14 Cf. Engelmann (2013). Assumimos neste texto a expressão "gramática-fenomenológica" de Engelmann para se referir, de modo geral, ao projeto da análise de uma linguagem fenomenológica (a qual inclui os testemunhos subjetivos) por meio exclusivamente da análise gramatical. A expressão "gramática-fenomenológica" nos mostra que há, então, uma transição entre a ideia de uma linguagem fenomenológica (descrita por meio de um simbolismo perspícuo) para uma gramática-fenomenológica (uma análise das regras gramaticais que se aplicam à linguagem fenomenológica, a exemplo dos testemunhos subjetivos). A descrição, assim, deixa de ser uma descrição dos fenômenos para se tornar uma descrição das regras gramaticais.
} 
A linguagem fenomenológica (conhecida como primária) seria um modo diferente de representação em relação à linguagem da física ou fisicalista (conhecida como secundária). A tese que Wittgenstein sustenta diz, desse modo, que a linguagem fisicalista seria uma construção teórica que descreveria a relação de objetos e suas propriedades no mundo a partir de uma descrição que estaria além do que é imediatamente dado pela percepção. Nesse sentido, a verificação das proposições fisicalistas seriam, para Wittgenstein, parciais e hipotéticas, porque a descrição de fenômenos, do tipo, 'mesa', 'livro' etc., não seria a descrição de objetos imediatamente apreendidos qua fenômenos, mas apenas aspectos gerais do que chamamos de 'mesa', 'livro', etc. ${ }^{15}$ Portanto, qualquer proposição sobre esses fenômenos, que não são imediatamente dados à percepção, seria hipotética. Wittgenstein traça, assim, uma distinção entre proposições empíricas relativas à linguagem fisicalista e testemunhos subjetivos relativos à linguagem fenomenológica, de modo que as proposições fisicalistas seriam, ao fim, traduzidas em proposições fenomenológicas.

Nesta distinção ainda está presente a tese da descrição apresentada no projeto da linguagem fenomenológica. Afinal, a linguagem fenomenológica, nas Observações, descreveria os fenômenos de um modo que a linguagem fisicalista não seria capaz, a saber, de um modo mais preciso, de tal forma que qualquer proposição empírica, por envolver hipóteses, seria tributária a proposições fenomenológicas. Nesse sentido, a motivação do sistema de coordenadas, como uma descrição simbólica/notacional, está ainda presente nas Observações. A diferença substancial, como argumentamos, é que Wittgenstein claramente diz que não é preciso construir um simbolismo perspícuo para essas proposições (para a sua descrição), porque tal tarefa deve ser realizada, de acordo com as Observações, pelo próprio esclarecimento gramatical. Há uma mudança clara entre a descrição simbólica/notacional de 1929, para uma descrição gramatical, ${ }^{16}$ a partir de 1930.

Um modo efetivo de entender a relação entre a tese da descrição e o esclarecimento gramatical, a partir dessa nova forma de tratar a linguagem nas Observações, é pensar no octaedro das cores. A análise das cores, pensada a partir da gramática do octaedro, ${ }^{17}$ deixa de ser feita por meio de um sistema de coordenadas no campo visual, como em 1929, e passa a ser pensada como uma gramática - "O octaedro das cores é gramática, já que diz que se pode falar de um azul avermelhado mas não de um verde avermelhado etc." (WITTGENSTEIN, 2005, p. 59). O que faz o octaedro é determinar o que tem sentido ou não dentro da gramática das cores. Ele evita, assim, a formação de absurdos - "Usar o octaedro como representação oferece-nos uma visão simultânea do todo e das partes das regras gramaticais" (Ibidem, p. 38). Em resumo, o octaedro é pensado por

${ }^{15}$ Cf. Engelmann (2013, p. 7).

${ }^{16}$ Cf. Carvalho (2013).

17"Modelos cromáticos diversos (octaedros, duplos cones, círculos) são analisados de forma minudente por Wittgenstein, que neles reconhece uma representação panorâmica de regras gramaticais acerca do emprego dessas expressões que descrevem nossa percepção. Desse modo, como a essência se expressa na gramática, as observações gramaticais de Wittgenstein sobre cores exploram, em parte, o conjunto de regras que a forma dos modelos exibe e, logo, o que faz sentido dizer com palavras para cores, que espécie de objeto uma cor pode ser" (SILVA, 2000, p. 89). 
Wittgenstein como uma figura sólida que serve para descrever o espaço lógico das cores, mostrando, assim, as relações possíveis entre elas (graus de brilho e saturação e/ou relações de uma cor com outras, por exemplo) $)^{18}$.

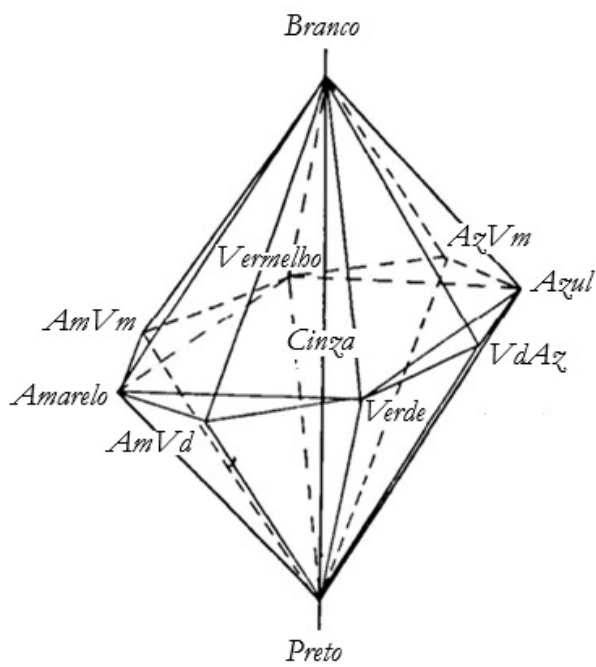

Figura 2

O que o octaedro mostra é a possibilidade da variação da cor amarela em direção à cor vermelha (passando pela cor laranja), ao mesmo tempo em que mostra que a variação da cor vermelha em direção à cor verde é impossível - um contrassenso $^{19}$. Essa impossibilidade, de ordem interna à gramática das cores, tem um caráter necessário. Não podemos obter uma proposição, do tipo, "A é vermelho e verde" ao mesmo tempo, simplesmente, porque, conforme nos diz o campo visual, há uma impossibilidade espaço-temporal; e, sim, porque a própria relação entre as estruturas das cores, representada pelo octaedro, mostra que esse tipo de formulação é um absurdo. Ele mostra, pelo esclarecimento gramatical, o que pode ser feito ou não.

Mas essa representação, embora diga o que faz sentido ou não, não é perspícua porque não envolve métrica ${ }^{20}$. Não diz que o amarelo $a$, por exemplo, é duas vezes mais amarelo que o amarelo (2b). O octaedro é apenas topológico. No caso, cada extremo do octaedro é de um determinado tipo (representa uma determinada cor) que, pelo modo como é construído o sistema, mostra quais combinações podem ou não ser feitas. Precisamente, aquilo que faz ou não sentido. Mas, não mostra, assim, todas as possiblidades entre azul e branco, por exemplo, em relação à gradação (ao brilho, à matiz, à saturação, etc.).

O octaedro torna explícita a estrutura do conceito de 'cor'. Em um dos polos, o branco; no outro, o preto. Em cada um dos cantos principais, o quadrado central, o octaedro mostra uma das cores primárias, na sequência vermelho, amarelo, verde e azul. Entre duas cores primárias as cores

${ }^{18}$ Cf. Engelmann (2013), Engelmann (2014) e Gonçalves (2016).

19 Cf. Gonçalves (2016).

${ }^{20}$ Cf. Cuter (2017 e 2009). 
intermediárias (por exemplo, amarelo-esverdeado). A vantagem do octaedro em relação a outras formas de representação é, para Wittgenstein, a perspicuidade do mesmo. Ele mostra, por exemplo, que existe uma assimetria entre as cores primárias e suas combinações (ENGELMANN, 2013, p. 32).

No entanto, diferentemente do projeto da linguagem fenomenológica, Wittgenstein não está interessado na construção de um simbolismo perspícuo. A gramática das cores do octaedro, por exemplo, é importante porque elucida a proposta de Wittgenstein, mas ele mesmo diz, nas Observações, que qualquer gramática que cumpra tal papel deverá ser considerada. Assim, a gramática do octaedro não deve ser assumida como a única possível que estabeleceria as relações gramaticais necessárias entre as cores primárias, por exemplo. Qualquer gramática que representasse estas relações poderia ser usada. Afinal, qualquer gramática que, pelo esclarecimento gramatical, evitasse a formulação de absurdos (separando o que é essencial do que não é essencial) funcionaria, ao fim, como parte essencial de "nossa linguagem".

Por esclarecimento gramatical, Wittgenstein entende, como vimos, a separação dos conteúdos fenomênicos (ou primários) dos conteúdos fisicalistas (ou secundários) nas proposições. ${ }^{21}$ Wittgenstein, portanto, não está em busca de um único simbolismo, mas do esclarecimento de diferentes gramáticas. Esta proposta se mantém no Big Typescript como uma investigação acerca dos diferentes sistemas de regras gramaticais e de seus respectivos usos. Na próxima seção veremos como as questões fenomenológicas das quais Wittgenstein se ocupava em 1929 e 1930 assumem exclusivamente, em meados de 1931 a 1933, a forma de uma investigação de ordem estritamente gramatical. Em resumo, veremos como Wittgenstein passa da fenomenologia à gramática. Veremos, então, como questões sobre a descrição de fenômenos no campo visual levaram Wittgenstein da formação de uma linguagem fenomenológica (como um sistema de coordenadas) e da descrição de diferentes gramáticas (como o projeto da gramática-fenomenológica nas Observações) à "fenomenologia é gramática" no Big Typescript.

\subsection{Gramática da 'PercepÇÃo'}

Nas seções anteriores vimos que em 1929, Wittgenstein, a partir das críticas de Ramsey, retorna a Cambridge para tratar de questões relativas ao campo visual. Neste contexto, o problema da percepção se restringe aos casos nos quais a notação do Tractatus seria insuficiente para tratar, de modo a priori

\footnotetext{
${ }^{21} \mathrm{~A}$ discussão sobre fenomenologia que fazemos aqui se restringiu, brevemente, aos capítulos iniciais das Observações. Há, nos capítulos XX e XXI, uma clara retomada dos temas ligados à fenomenologia, em especial, à gramática das cores a ao campo visual. Mas, nesta breve seção, não iremos discutir estes capítulos porque nosso objetivo, como dissemos, é entender a questão da descrição em relação ao esclarecimento gramatical para, a partir disso, entender como ela é realocada no Big Typescript e no texto Linguagem Fenomenológica. Para ver, de modo geral, como essas questões são tratadas nas Observações, conferir, Carvalho, M \& Engelmann, M \& Cuter, J \& Neto, B (2017).
} 
(verocondicional), de proposições que envolvessem gradações, como no caso das cores. Este problema na notação de 1921 o obriga a elaborar uma linguagem perspícua para tratar destes casos-limites. O projeto da linguagem fenomenológica, no entanto, não é levado a cabo, sendo pouco tempo depois substituído, nas Observações, pela análise gramatical ou projeto da gramática-fenomenológica que, por sua vez, também é abandonado posteriormente. ${ }^{22}$ Wittgenstein, apesar de abandonar ambos os projetos, não abandona o problema da percepção. O problema assume, explicitamente, no Big Typescript (1932-33) e no texto Linguagem Fenomenológica (1931-34), a forma de uma investigação exclusivamente gramatical. Trata-se, assim, de diferentes sistemas gramaticais, de sua convergência e divergência, da formulação de pseudoproblemas, dentre outras coisas. Além, é claro, da percepção como uma questão relativa ao campo visual. ${ }^{23}$ Mas, diferentemente das Observações, onde essas questões já estavam em parte presentes, outra questão opera agora de maneira mais explícita, a saber, a generalidade. ${ }^{24}$ Esta nova concepção de generalidade (da percepção) tem, como veremos, uma implicação direta na ideia de análise empreendida por Wittgenstein neste período.

Na seção 94 do Big Typescript, denominada Fenomenologia, Wittgenstein assume claramente que "fenomenologia é gramática" (BT 442). Ser 'gramática' significa duas coisas: primeiro, que fenomenologia pertence a um sistema de regras, pois, para Wittgenstein, 'gramatica' é sinônimo de "sistema de regras" (BT $257 \mathrm{v}$ ); e, segundo, que sistemas determinam o que pode ser formulado com sentido e o que não pode ser formulado.

Contudo, há um problema na própria expressão "fenomenologia é gramática". ${ }^{25}$ Afinal, se "fenomenologia é gramática", Wittgenstein certamente não tem em mente o projeto da linguagem fenomenológica de 1929. Não se trata, assim, da elaboração de um simbolismo perspícuo. Por outro lado, se não se trata da formulação de um simbolismo, não se trata também de pensar a fenomenologia como descrição de fenômenos - como ocorre com a tradição, sobretudo, com a fenomenologia de Husserl. Se "fenomenologia é gramática", então Wittgenstein parece ter em mente um modo de explicar como a gramática, que se ocupa de regras (a priorì), diz algo sobre fenômenos que são, naturalmente, a posteriori. "Fenomenologia é gramática" não trata, então, de dizer sobre quais fenômenos podem ou não ser formados (como uma espécie de impossibilidade ontológica), nem de dizer como eles são formados. Trata-se antes de dizer se faz sentido ou não dizer, por exemplo, que "vejo, perfeitamente, uma figura de 100 lados" (BT, 440). Afinal, em um contexto empírico faz sentido dizer que "há uma figura de 100 lados" e que podemos vê-la perfeitamente ou não. Mas, em um contexto de

${ }^{22}$ Cf. "expectativa, tempo e memória” em Neto (2003), Gomes (2011) e Ghizoni (2013).

${ }^{23}$ Conforme já dissemos na introdução do texto, nosso objetivo é tratar da relação entre o problema da percepção visual e o problema da gramática da 'percepção'. Não sustentamos, com isso, que Wittgenstein restringe o problema da percepção ao problema da percepção visual, sobretudo, do campo visual.

24 Wittgenstein, nas Observações, capítulo IX, trata da questão da generalidade em relação à fenomenologia. Mas nosso interesse é em relação ao que ele diz no Big Typescript. Para ver sobre a generalidade, no capítulo IX, cf. Cuter (2017, p. 205-228).

${ }^{25}$ Cf. Hintikka (1994, p. 193-197) e Monk (2014, p. 312-340). 
proposições fenomenológicas, de testemunhos subjetivos, não faz sentido dizer que "vemos, perfeitamente, uma figura de 100 lados". Nesse caso, a impossibilidade não diz respeito ao campo visual, mas somente à gramática, pois, aqui, são gramáticas distintas operando e, portanto, são sistemas de regras diferentes. Não faz sentido dizer, assim, que "vemos, perfeitamente, uma figura de 100 lados", porque o advérbio "perfeitamente" não deveria ser aplicado, neste caso, ao testemunho subjetivo. A menos, é claro, que aquele que vê a figura (sua própria percepção) seja uma espécie de "olhador prodígio" e consiga distinguir, perfeitamente, uma figura de 100 lados de outra de 99, 98, 97 lados, etc., ou ainda, de 101, 102, 103, etc. Dito de forma mais clara, "fenomenologia é gramática" trata da maneira como descrevemos gramaticalmente (com sentido) os fenômenos.

Fenomenologia como gramática, nesse sentido, parece assumir o papel que a análise desempenhava antes. A análise, por um lado, nos permitia levar a cabo a análise proposicional e, por outro, evitava a formulação de absurdos. "Fenomenologia é gramática" cumpre, de modo semelhante, aquilo que a análise cumpria. Afinal, por um lado, nos permite evitar a formulação de absurdos ao dizer o que faz ou não sentido ser formulado e, por outro, nos permite levar a cabo a análise proposicional. No entanto, diferentemente do Tractatus e do projeto de 1929, Wittgenstein, como vimos, assume que esta análise diz respeito à gramática. No Big Typescript, como veremos, a análise diz respeito exclusivamente ao entendimento do sistema de regras do qual a proposição faz parte e do entendimento daquilo que pode ou não ser formulado neste sistema. Para elucidar a expressão "fenomenologia é gramática", Wittgenstein oferece como exemplo, novamente, a gramática das cores do octaedro.

O espaço das cores é representado por um octaedro [...] essa representação é gramatical, não psicológica. [...] O octaedro de cor é uma gramática porque nos diz que podemos falar sobre um azul avermelhado, mas não sobre um verde avermelhado, etc. A representação, via octaedro, é uma representação surveyable das regras gramaticais (BT 441 , grifos nossos).

A representação do octaedro é gramatical, então, naturalmente, não é psicológica. Não se trata do modo como percebemos as cores, mas do modo como elas são representadas (ou podem ser representadas) pelo octaedro. Sendo assim, certas combinações são possíveis enquanto outras não. Se usamos a gramática do octaedro para representar as cores, não podemos, evidentemente, usar outro sistema simultaneamente - a menos que, como vimos nas Observações, os sistemas sejam compatíveis e separem o que é essencial do que não é essencial. Afinal, cada sistema diz respeito apenas ao que pode ou não ser gerado pelo seu próprio sistema. Há, no entanto, dois problemas. Primeiro, o octaedro não envolve métrica (conforme vimos na seção 1.2). Segundo, tendemos a confundir os sistemas, as gramáticas. Tendemos, por exemplo, a usar a palavra 'localização' e 'cor', ora em relação ao campo visual, e ora em relação a descrições físicas. Nestes casos, faltanos clareza, acredita Wittgenstein, em relação ao uso das gramáticas.

O que nos perturba é a falta de clareza sobre a gramática da sentença "vejo dois círculos vermelhos em um fundo 
azul" - em particular, suas relações com a gramática de sentenças, tais como, "duas bolas vermelhas estão em cima da mesa" e "vejo duas cores nesta foto" (BT 438, grifos nossos).

Confundimos, aqui, o uso de sentenças empíricas que dizem "duas bolas vermelhas estão em cima da mesa" com "vejo duas cores nesta foto", ou ainda "vejo dois círculos vermelhos sobre um fundo azul". No primeiro caso, dizer que há "duas bolas vermelhas em cima da mesa" nos compromete com a localização espaço-temporal do que afirmamos. A gramática de sentenças empíricas, como no exemplo acima, é completamente diferente de sentenças que afirmam que "vejo duas cores nesta foto" ou "vejo dois círculos vermelhos em um fundo azul". Neste segundo caso estamos tratando do campo visual, daquilo que vemos, portanto, estamos tratando de testemunhos subjetivos. A gramática que opera aqui, em relação à palavra 'localização', é totalmente distinta da usada pela proposição empírica. É distinta também a questão do tempo no contexto dos testemunhos subjetivos. Dizer "vejo duas cores nesta foto" não é um evento estendido temporalmente. Testemunhos subjetivos são imediatos, pois, dizer "vejo duas cores" significa que "vejo agora duas cores", não que vi ${ }^{26}$, no tempo $\mathrm{T}_{1}$, duas cores, e elas se mantiveram no tempo $\mathrm{T}_{2}$. Também não significa que "vejo duas cores agora" e lembro das duas cores que vi antes. Em contextos empíricos, que são temporalmente estendidos, podemos falar de algo que ocorreu e dizer se este algo ainda ocorre. Em contextos de testemunhos subjetivos, ou seja, em um contexto interlocutório, todo testemunho é imediato. Assim, se há gramáticas distintas, como vimos acima, como então pode ser tratada a gramática do campo visual e, por conseguinte, da percepção?

No texto Linguagem Fenomenológica, Wittgenstein diz que o problema de descrever o campo visual parecia, a princípio, que estava relacionado a "uma dificuldade técnica, a saber, a inexatidão da linguagem de palavras" (WITTGENSTEIN; WAISMANN, 2003, p. 313). O sistema de coordenadas para o campo visual, em 1929, pretendia eliminar justamente esta inexatidão. Por isso, para Wittgenstein, os números deveriam fazer parte da forma lógica das proposições elementares, porque, desta forma, teríamos como levar a cabo a análise de proposições que envolvessem gradações. Durante os anos de 1929 a 1930, Wittgenstein estava interessado nesta questão, sobretudo na construção de um simbolismo perspícuo para lidar com a inexatidão da linguagem fenomenológica. O motivo diz respeito, evidentemente, ao projeto verocondicional do Tractatus. Afinal, se proposições têm sentido (um sentido definido), então deveríamos ter condições de realizar uma análise lógica que nos permitisse mostrar, com precisão, as condições de verdade das proposições analisadas. O pano de fundo desta posição diz respeito ao fato de que proposições elementares são funções de verdade de proposições complexas e, como vimos, diz respeito também ao fato de proposições terem um sentido definido.

O projeto da linguagem fenomenológica de 1929 foi realizado para enfrentar estas questões. O simbolismo do sistema de coordenadas era, assim, um

\footnotetext{
${ }^{26}$ Um testemunho subjetivo envolve sempre a primeira pessoa do singular.
} 
complemento do simbolismo de Tractatus. Nas Observações, no entanto, Wittgenstein não estava mais preocupado com a formulação de um simbolismo perspícuo baseado em uma linguagem fenomenológica (porque não o julgava mais como imprescindível), embora, por outro lado, ainda estivesse interessado na exatidão. O projeto de gramática-fenomenológica tinha como objetivo trazer para dentro do esclarecimento gramatical, das regras implícitas em cada gramática, a exatidão da descrição de proposições fenomenológicas - e também empíricas, pois, como vimos, a verdade e falsidade destas proposições dependeria do esclarecimento das proposições fenomenológicas.

Wittgenstein, no Big Typescript e também no texto Linguagem Fenomenológica, não está mais preocupado com a exatidão da linguagem fenomenológica. Um dos motivos diz respeito ao fato da ideia de sistemas gramaticais não pressupor, em nenhum momento, a tese verocondicional do Tractatus e, consequentemente, porque Wittgenstein assume agora, explicitamente, a tese da generalidade. E o outro motivo diz respeito aos fazedores de verdade (truth-makers) de proposições fenomenológicas. O problema dos fazedores de verdade é, basicamente, um reflexo do novo tratamento da generalidade. Adiantando um pouco a tese da generalidade que será discutida a seguir, devemos pensar que, se assumimos que percepções são gerais, então não faz sentido dizer que o sentido proposicional é composto, por um lado, pela análise proposicional e, por outro, pela análise ou decomposição de percepções. O fazedor de verdade (truth-maker) de uma percepção seria algo igualmente geral.

Na abertura da seção "Generalidade", do Big Typescript, Wittgenstein diz que "A proposição 'O círculo está no quadrado' é, em certo sentido, completamente independente da atribuição de uma sentença particular" (BT 312, grifos nossos). Isto significa que, diferentemente do Tractatus, o sentido da proposição geral "o círculo está no quadrado" não seria determinado, no processo de análise proposicional, por casos particulares. Wittgenstein nega, nesta passagem, a tese verocondicional de 1921 quando tratamos de casos gerais. O que daria sentido à proposição geral "o círculo está no quadrado" é distinto e independente do que daria sentido a qualquer proposição particular, que diz que "o círculo está no quadrado x, na posição y". Dito de outra forma, Wittgenstein acredita que o sentido da proposição geral não seria determinado pela disjunção de casos singulares (BT 318). Assim, se não podemos determinar o sentido de uma proposição geral pela disjunção de casos singulares, então o sentido de uma proposição deste tipo dependeria apenas da possibilidade de sua negação, ou seja, de que "não há um círculo no quadrado" (BT 316). Afinal, somente uma representação geral poderia, neste caso, negar uma outra representação geral.

No entanto, como diz Wittgenstein, o interlocutor ainda poderia se sentir inclinado a dizer que tem condições de dar uma singularização de uma proposição geral. Ele poderia dizer, por exemplo, que "se há um círculo no quadrado, deve estar em algum lugar e ter algum tamanho" (BT 314). Ou seja, se a proposição geral anuncia "algo", deveríamos ter condições de explicitar o que é. Wittgenstein, no entanto, tem uma posição distinta e acreditamos que ele parece negar, neste caso, duas coisas: primeiro, que na forma lógica da proposição geral poderíamos 
explicitar quais são estas condições que o interlocutor exige. Com isso, Wittgenstein não concorda com a ideia de que todas as condições que o interlocutor exige estão presentes, na proposição, como pertencentes à sua forma lógica, pois acredita que o que a proposição geral anuncia é, na verdade, apenas um sentido geral. Segundo, Wittgenstein também parece discordar que por detrás de uma proposição geral haveria uma espécie de impressão particular que filtraria, como uma peneira, aquilo que seria importante para compor o sentido da proposição. Wittgenstein diz:

Trata-se, antes, da ideia de que na primeira posição pareço passá-los por uma espécie de peneira de modo que o "círculo em um quadrado" corresponda a uma única impressão que não leva em conta o onde, etc., como se fosse (contra toda a aparência) algo apenas fisicamente, não logicamente, ligado ao primeiro estado de coisas (BT 315, grifos nossos).

Nesta passagem Wittgenstein diz que não faz sentido perguntar por qual peneira passou a impressão (a única impressão) que corresponde ao sentido da proposição. Ou seja, não faz sentido tentar encontrar qual foi a impressão que contribuiu para compor o sentido da proposição. Como vimos, não faz sentido esta pergunta porque as impressões singulares não são pertencentes às proposições gerais. Como não há uma disjunção de casos singulares que formam um caso geral, não há também uma disjunção de impressões singulares que formam uma impressão geral. Wittgenstein sustenta, aqui, que proposições gerais e singulares são dois sistemas lógicos distintos e possuem, desse modo, gramáticas distintas. Então não faz sentido, assim como faz no caso de proposições empíricas, tentar fazer uma análise nas percepções para encontrar, ao fim, um "mínimo perceptível" que funcionaria como aquilo que determinaria o sentido dos testemunhos subjetivos. ${ }^{27}$

Neste ponto damos mais um passo em relação ao problema da percepção, pois, Wittgenstein, ao reconhecer no Big Typescript que proposições gerais não têm seu sentido determinado pela disjunção de casos particulares, reconhece também que é a impressão geral que constitui o sentido destas proposições gerais. Wittgenstein, portanto, passa da tese da proposição geral para a tese da percepção geral. Sobre esta questão, Wittgenstein, no texto Linguagem Fenomenológica, nos dá um importante exemplo:

Imaginemos que uma pessoa olhe para o céu por um instante e então é perguntada sobre quantos pontos de luz ela viu. Haveria aqui uma resposta da forma: "Vi $n$ pontos de luz"? Isto é, "Não sei quantos pontos de luz havia lá, mas claramente devo ter visto algum número definido"? Diríamos: Aqui não faz o mínimo sentido falar de um número definido (WITTGENSTEIN e WAISMANN, 2003, p. 317 , grifos nossos).

\footnotetext{
27 Apesar dos testemunhos subjetivos, no período intermediário, terem um importante papel em relação aos fazedores de verdade (eles são os fazedores de verdade, para o Wittgenstein deste período), não faz sentido alegar que impressões poderiam ser decompostas.
} 
Por que não faria sentido dizer que o interlocutor viu um número definido de estrelas? De um certo modo, ele viu pontos, como estrelas, no campo visual. Se viu pontos, então, mesmo que não fosse capaz de dizer quantos exatamente, ainda assim faria sentido dizer que ele viu um número definido. Wittgenstein, no entanto, discorda desta posição. Vamos imaginar, por exemplo, que o interlocutor ao invés de dizer quantas estrelas viu, nos oferece uma tela pintada (uma representação). Poderíamos perguntar, neste caso, se, de acordo com essa representação, há mais estrelas no canto direito ou esquerdo da tela, ou quais estrelas tem mais brilho, etc. Podemos exigir do interlocutor um grau de detalhamento cada vez maior, embora não faça sentido um detalhamento completo da tela (uma espécie de completude da tela). No entanto, diferentemente de uma representação (que é, neste caso, uma tela física), não podemos exigir cada vez mais detalhamento da impressão que o interlocutor teve. A percepção visual, a impressão do interlocutor, é instaurada instantaneamente. Não faz sentido pedir ao interlocutor que retorne novamente à mesma impressão e diga quantas estrelas viu porque, simplesmente, ele não é capaz de dar um grau de detalhamento satisfatório. Ele pode naturalmente dizer um número qualquer, mas se exigirmos mais detalhamento haverá um momento em que não fará mais sentido para o interlocutor responder. Não fará sentido porque, simplesmente, ele será incapaz de fazê-lo. Por isso, argumenta Wittgenstein, não faz sentido dizer "Vi $n$ pontos de luz", pois, na verdade, o interlocutor não sabe quantos pontos de fato viu.

A posição de Wittgenstein em relação ao exemplo do céu estrelado nos diz que é um absurdo (não faz sentido) pensar "que a experiência seja determinada em todos os sentidos" (WITTGENSTEIN e WAISMANN, 2003, p, 319). Ou seja, que não faz sentido pensar que o interlocutor tenha visto de fato um número determinado de pontos de luz e que o único motivo pelo qual ele não diz quantos eram é porque há alguma dificuldade técnica, por exemplo, que não se lembra. Wittgenstein, contrariamente à tradição, ${ }^{28}$ acredita que impressões são inerentemente gerais. Portanto, não faz sentido, como no exemplo acima, pensar que o interlocutor tem uma impressão singular das estrelas no céu (então, por isso, deveria dizer exatamente quantas viu), nem que a impressão geral fosse composta por impressões singulares. Pensar a questão nestes termos é tratar a impressão como uma representação. Como vimos, podemos exigir de representações um grau de detalhamento cada vez maior, mas, por outro lado, não podemos exigir de impressões este mesmo grau de detalhamento. O motivo se deve ao fato de que representações são sempre singulares e impressões sempre gerais. Impressões expressam a "experiência fugaz" (Ibidem, p, 313).

A descrição do meu campo visual, mesmo que eu a dê em palavras, em um desenho, ou de alguma outra forma, será sempre aproximada, grosseira, inexata - mas cada uma de uma forma diferente (Ibidem, p, 321).

A palavra 'aproximada' aqui funciona de modo distinto de outros contextos, por exemplo, de descrições empíricas. No contexto de descrições empíricas, 'aproximadamente' corresponde à 'exatamente'. No caso do campo visual, de

${ }^{28}$ Por exemplo, Kant. Cf. Porto (2012, p. 76). 
testemunhos subjetivos, a palavra 'aproximadamente' corresponde apenas em um certo sentido à palavra 'exatamente'. Afinal, como dissemos acima, não faz sentido decompor a percepção em unidades menores que determinariam o sentido de um testemunho subjetivo e que, por conseguinte, nos asseguraria a exatidão da descrição. O que Wittgenstein argumenta, portanto, é que quando abandonamos nossa busca por exatidão vemos, nestes contextos, que a "linguagem está completamente em ordem (como ela é) e que essa busca por uma linguagem ideal não é nada mais do que uma aberração causada por uma analogia enganadora" (Ibidem, p. 318, grifos nossos). O problema da percepção não diz respeito a uma incapacidade de nossa linguagem, mas, antes, a uma má formulação do problema. Dito de outra forma, refere-se à confusão gerada entre a gramática da palavra 'aproximadamente' e 'exatidão'. Parte deste problema se baseia na tese equivocada de que dar uma descrição é sinônimo de exatidão. Como argumentamos, a partir do texto de 1929, era justamente esta postura em relação à descrição que motivava Wittgenstein.

\section{CONSIDERAÇÕES FINAIS}

Neste texto argumentamos que, no período intermediário, a questão da percepção visual (sobretudo, do campo visual) era central para Wittgenstein por causa da ideia de descrição (e de sua relação com a formulação de um simbolismo perspícuo) que ele empreendeu nos anos 1929 e 1930. Como vimos, a exigência desse novo simbolismo nasceu como uma resposta a Ramsey e ao problema das proposições que envolvem gradação (como as cores) que, embora possam ser proposições elementares, não seriam logicamente independentes, porque se excluem. Argumentamos também que com a passagem da fenomenologia à gramática, Wittgenstein ocupou-se, a partir de então, da gramática da 'percepção'. Esta gramática assume, nas Observações, a forma de uma investigação em relação ao que é essencial e não essencial à linguagem (ou seja, em relação à distinção entre a linguagem primária e a secundária e seus diferentes modos de verificação), mas que mantém, de certa forma, a motivação da descrição; e, no Big Typescript, assume a forma de diferentes sistemas gramaticais e seus respectivos usos (como no caso daqueles que tratam de testemunhos subjetivos e de descrições empíricas).

Por fim, argumentamos que no texto Linguagem Fenomenológica, mas também no Big Typescript, Wittgenstein abandona de vez a tese da descrição e assume a questão da generalidade como central. No Big Typescript, Wittgenstein trata das proposições gerais e sustenta, diferentemente de como fizera no Tractatus, que o sentido de uma proposição geral não depende da disjunção de casos particulares, mas apenas de sua negação. Assumindo o caráter inerentemente geral destas proposições, Wittgenstein, no texto Linguagem Fenomenológica, passa da generalidade da proposição para a generalidade da percepção e assume, nesse sentido, que percepções são naturalmente gerais. Ou seja, que não podemos aplicar a elas o exame do detalhamento, como fazemos com as representações. Pelo contrário, é a tentativa de aproximar impressão de representação que gera grande parte das confusões sobre o problema da percepção (como ocorre, por 
exemplo, com a tradição e a tese de que impressões são uma espécie de imagem mental singular). Neste cenário, a motivação da descrição que, como vimos, estava por detrás do projeto da linguagem fenomenológica como um suporte à analise proposicional, é abandonada.

A conclusão que Wittgenstein sustenta no texto Linguagem Fenomenológica parece caracterizar bem como o problema da percepção é tratado, de modo geral, pela filosofia. Tendemos a confundir a gramática de expressões como 'aproximadamente' e 'exatamente', sobretudo, quando aplicadas a diferentes contextos, e nos sentimos inclinados a postular que somos sempre incapazes de dar uma descrição satisfatória, como se a linguagem ordinária (como pensara o próprio Wittgenstein) fosse insuficiente. Quando, na verdade, o problema surge, justamente, no modo como formulamos a questão da percepção e também, como sustentamos, a questão da descrição. Por isso, a gramática da 'percepção', como sustentamos no texto, é uma questão central no período intermediário - e, também, no período final. Ela dissolve uma postura cara à filosofia de que, ao dar uma descrição, estamos mais próximos do que queríamos de fato dizer ou mais próximos de como as coisas são (BT 249).

\section{REFERÊNCIAS BIBLIOGRÁFICAS}

AUSTIN, J. L. Sentido e percepção. 2. ed. Trad. Armando Manuel Mora de Oliveira. São Paulo: Martins Fontes, 2004.

BRANQUINHO, J. Percepção. In: Compêndio em linha de problemas de Filosofia Analítica. Lisboa: Universidade de Lisboa, 2014. p. 1-23.

CARVALHO, M. Phenomenological language and the description of visual space. O Que nos Faz Pensar, n. 33, p. 205-234, jun. 2013.

CARVAlho, M; ENGELMANN, M; CUTER, J.V; NETO, B. P. Fenomenologia, análise e gramática: comentário às Observações Filosóficas de Wittgenstein (Parte 1). São Paulo: Mundaréu, 2017.

CUTER, J, V, G. Uma fenomenologia sem métrica. In: Fenomenologia, análise e gramática: comentário às Observações Filosóficas de Wittgenstein (Parte 1). São Paulo: Mundaréu, 2017. pp. 175-204.

Infinitude, generalidade e fenômeno. In: Fenomenologia, análise e gramática: comentário às Observações Filosóficas de Wittgenstein (Parte 1). São Paulo: Mundaréu, 2017. p. 205-228.

As cores e os números. Dois Pontos, Curitiba, v. 6, n. 1, p. 181-193, abril 2009.

ENGELMANN, M. Anpassung: o projeto gramático-fenomenológico das "Observações Filosóficas". In: MORENO, Arley R. (org.). Wittgenstein e a epistemologia. Campinas: CLE, 2013. p. 29-58.

Verificacionismo e "mito do dado" no contexto das Observações Filosóficas. Analytica, Rio de Janeiro, v. 18, n. 2, p. 13-40, 2014. 
GONÇALVES, A. Do Tractatus às Observações Filosóficas: reflexões sobre a natureza da Filosofia, 2016 (no prelo).

GOMES, C, A. "Sentido" e "impressão" em Wittgenstein. Dissertação (Mestrado em Filosofia) - Faculdade de Filosofia e Ciências Sociais da Universidade Federal de Goiás, Goiânia, 2011.

GHIZONI, G, S. O fim da fenomenologia em Wittgenstein: uma abordagem temporal. Philósophos, Goiânia, v. 18, n. 2, p.11-41, jul./dez. 2013.

HINTIKKA, J., \& HINTIKKA, M. Uma investigação sobre Wittgenstein. Campinas: Papirus Editora, 1994.

NETO, B, A, P. Fenomenologia em Wittgenstein: tempo, cor e figuração. Rio de Janeiro: UFRJ, 2003.

MACHADO, A. N. Lógica e forma de vida: Wittgenstein e a natureza da necessidade lógica e da Filosofia. São Leopoldo: Unisinos, 2004.

MONK, R. The temptations of phenomenology: Wittgenstein, the synthetic a priori and the 'analytic a posteriori'. British Journal for the History of Philosophy, v. 22. n. 3, p. 312-340, 2014.

MORENO, A. Descrição fenomenológica e descrição gramatical: ideias para uma pragmática filosófica. Revista Olhar, ano 4, n. 7, p. 93-139, jun-dez, 2003.

PORTO, A. Singularity and visual perception. Philosophiques, v. 39, n. 1, p. 75$100,2012$.

RAMSEY, F. Resenha ao Tractatus Logico-Philosophicus de Wittgenstein. Trad. Marcos Silva. Philósophos, Goiânia, v. 17, n. 2, p. 263-288, jul./dez. 2012.

SILVA, J, S. Sobre a gramática das cores em Wittgenstein. Ideação, Feira de Santana, n. 4, p. 87-94, jan/jun. 2000.

WAISMANN, F. Wittgenstein and the Viena Circle. Oxford: Basil Blackwell, 1979.

WITTGENSTEIN, L. Notebooks, 1914-1916. 2. ed. Oxford: Basil Blackwell, 1979.

. Some remarks on logical form. In: Philosophical occasions (1912-1951). Indianapolis: Hacket Publishing Company, 1993. p. 28-36.

1999.

Investigações filosóficas. Trad. José Carlos Bruni. São Paulo: Nova Cultura,

The Big Typescript: TS 213. German-English Scholars' Edition. Luckhardt, G and. Maximilian, A. E. (ed. and trans). Oxford: Basil Blackwell, 2005.

Loyola, 2005.

Observações filosóficas. Trad. Sobral, A. e Gonçalves, M. São Paulo:

. Tractatus Logico-Philosophicus. 3. ed. Trad. Luiz Henrique Lopes dos Santos. São Paulo: Edusp, 2008.

WITTGENSTEIN, L; WAISMANN, F. Phenomenal language. In: The voices of Wittgenstein. London: Routledge, 2003. p. 313-21. 